\title{
PENGARUH BUDAYA KERJA KARYAWAN TERHADAP KINERJA KERJA
} PADA UNIT CARGO PT. GARUDA INDONESIA (DISTRIK JAKARTA RAYA)

\author{
Lalu Rentah Muzayinsam ${ }^{1}$, Ryan Firdiansyah ${ }^{2}$, Moch. Fatchoelqorib ${ }^{3}$ \\ Sekolah Tinggi Penerbangan Aviasi, Jakarta, Indonesia \\ Email : lalumuzayinsam@yahoo.co.id, ryan@stp-aviasi.ac.id, fatchoel@yahoo.com
}

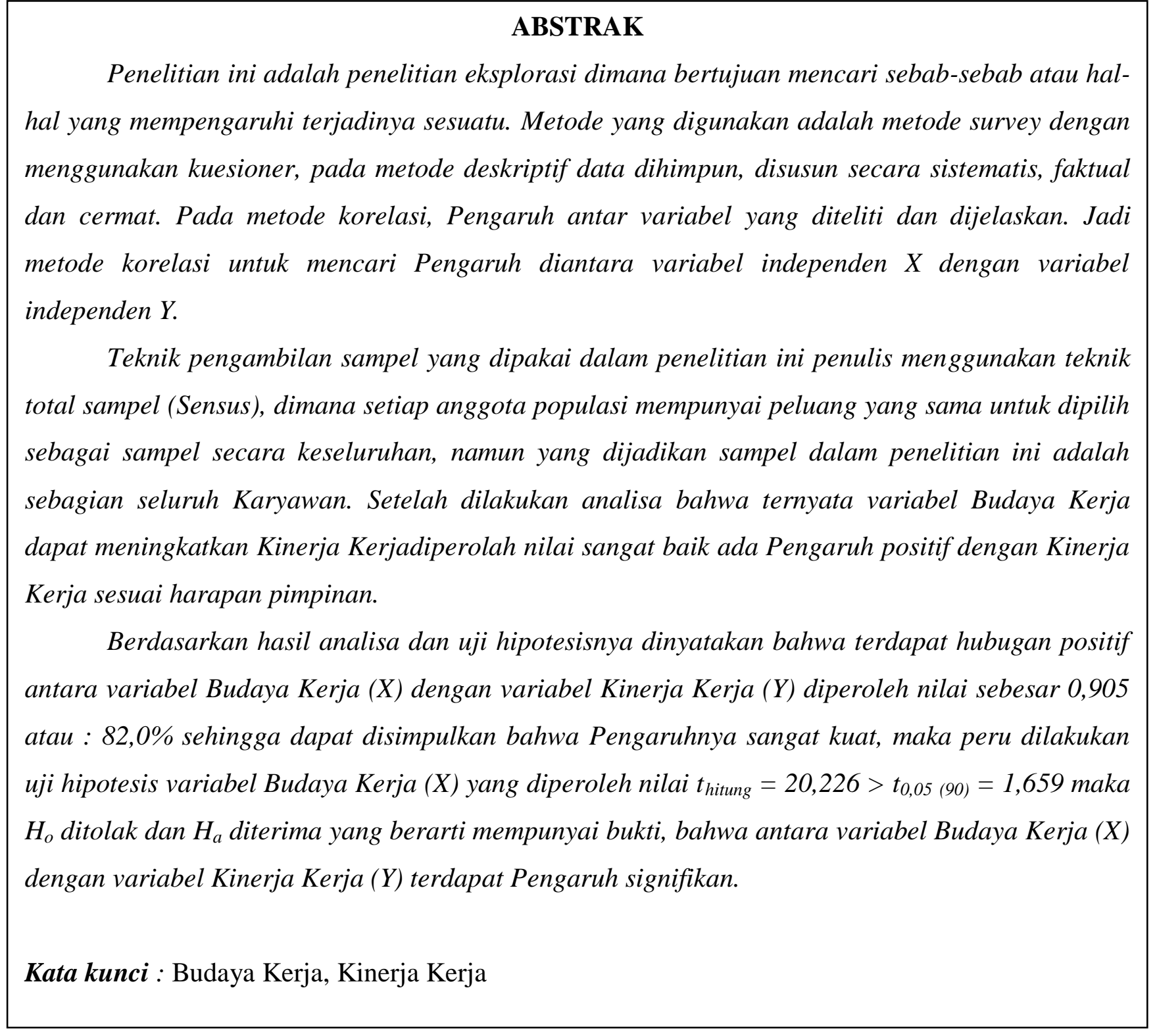




\section{PENDAHULUAN}

Perkembangan sumber daya manusia terbaru saat ini bukan hanya memandang sebagai sumber daya yang asal dalam perekrutan dan mengisi posisi yang kosong belaka, melainkan sumber daya manusia menjadi modal atau aset bagi institusi atau organisasi. Karena itu kemudian munculah istilah baru di luar Human Resources, yaitu Human Capital. Di sini Sumber Daya Manuasia dilihat bukan sekedar sebagai aset utama, tetapi aset yang bernilai dan dapat dilipatgandakan, dikembangkan (bandingkan dengan portfolio investasi) dan juga bukan sebaliknya sebagai liability (beban, cost). Di sini perspektif sumber daya manusia sebagai investasi bagi institusi atau organisasi lebih mengemuka.

Hal ini di unit cargo Garuda Indonesia selaku pemegang peranan dalam menciptakan budaya organisasi dalam mencapai suatu hasil kerja yang maksimal dan tercipta kinerja karyawan dalam bekerja. Budaya organisasi dapat mempengaruhi cara orang dalam berperilaku dan harus menjadi acuan dalam menyelesaikan tugasnya dan kebijakan yang akan diambil. Oleh karena itu budaya organisasi yang terbentuk sangat berpengaruh dalam cara berfikir dan bersikap karyawan dalam menyelesaikan suatu pekerjaan dan juga dalam menyelesaikan suatu masalah. (Dudi Hendaryan, Denti Yulianti, 2018).
Sumber daya manusia merupakan sektor sentral dan penting dalam rangka pencapaian tujuan di suatu perusahaan, karena dengan adanya kemampuan skill para pekerja dan kualitas sumber daya manusia dapat menggerakan perusahaan dengan baik dan benar. Kemampuan teknologi juga merupakan unsur penunjang penting dalam menggerakan perusahaan, karena dengan adanya kelengkapan teknologi dan kecanggihan teknologi akan memudahkan berjalannya suatu perusahaan. Dari keempat sumber tersebut aspek yang terpenting yaitu manusia, karena manusia merupakan penggerak terpenting dalam perusahaan. Maju atau tidaknya perusahaan tergantung pada pengelolaan sumber daya manusia ini dapat dilakukan dalam suatu perusahaan itu atau oleh suatu departemen tertentu.

Salah satu hal yang dapat ditempuh adalah kualitas sumber daya manusia. Peranan sumber daya manusia dalam organisasi sangatlah penting karena penggerak utama seluruh kegiatan atau aktivitas instansi dalam mencapai tujuannya. Berhasil tidaknya suatu instansi dalam mempertahankan eksistensi instansi dimulai dari usaha manusia itu sendiri dalam meningkatkan efektivitas dan efisiensi secara maksimal.

Budaya Kerja adalah merupakan sikap mental yang selalu mencari perbaikan atau 
penyempurnaan apa yang telah dicapai, dengan menerapkan teori-teori dan metode-metode baru serta yakin akan kemajuan umat manusia. Budaya kerja sudah lama dikenal umat manusia, namun belum disadari bahwa suatu keberhasilan kerja itu berakar pada nilai-nilai yang dimiliki dan perilaku yang menjadi kebiasaannya, antara lain adat kebiasaan, agama, norma dan kaidah. Budaya kerja itu tidak muncul begitu saja, akan tetapi harus diupayakan dengan sungguhsungguh melalui proses yang terkendali dengan melibatkan semua sumber daya manusia (SDM) dalam seperangkat system yang saling mendukung.

Budaya Kerja adalah merupakan sikap mental yang selalu mencari perbaikan atau penyempurnaan apa yang telah dicapai, dengan menerapkan teori-teori dan metode-metode baru serta yakin akan kemajuan umat manusia. Budaya kerja sudah lama dikenal umat manusia, namun belum disadari bahwa suatu keberhasilan kerja itu berakar pada nilai-nilai yang dimiliki dan perilaku yang menjadi kebiasaannya, antara lain adat kebiasaan, agama, norma dan kaidah. Budaya kerja itu tidak muncul begitu saja, akan tetapi harus diupayakan dengan sungguhsungguh melalui proses yang terkendali dengan melibatkan semua sumber daya manusia (SDM) dalam seperangkat system yang saling mendukung.
Kinerja merupakan aspek penting dalam upaya pencapaian suatu tujuan. Pencapaian tujuan yang maksimal merupakan buah dari kinerja tim atau individu yang baik. Begitu pula sebaiknya, kegagalan dalam mencapai sasaran yang telah dirumuskan juga merupakan akibat kinerja individu atau tim yang tidak optimal. Baik buruknya kinerja tidak hanya dilihat dari tingkat kualitas yang dapat dihasilkan seseorang dalam bekerja, akan tetapi juga diukur dari segi kualitasnya. Secara umum dapat dikatakan bahwa kinerja (performance) merupakan wujud atau keberhasilan pekerjaan seseorang atau organisasi dalam mencapai tujuannya. Hasil atau kinerja yang dicapai tidak hanya terbatas dalam ukuran kuantitas, namun juga kualitas. Peningkatan kinerja karyawan secara terus menerus akan memotivasi para karyawan. Kinerja berasal dari kata Job Performance atau Actual Performance (prestasi kerja atau prestasi sesungguhnya yang dicapai seseorang). Pada umumnya orang-orang yang berkecimpung dalam manajemen sumber daya manusia sependapat bahwa kinerja karyawan merupakan bagian penting dari seluruh proses kekaryaan karyawan yang bersangkutan. Anwar Prabu Mangkunegara (2002:67), mengemukakan bahwa : "Kinerja adalah hasil kerja secara kualitas dan kuantitas yang dicapai oleh seorang karyawan dalam melaksanakan tugasnya sehari- 
hari sesuai dengan tanggung jawab yang diberikan kepadanya".

Dari uraian di atas di dalam unit Cargo E PT. Garuda Indonesia (Distrik Jakarta Raya) hasil penilaian dari perusahaan masih rendah dengan berbagai macam faktor dan indikator, selain itu harapan Manager Cargo Service kepada karyawan untuk mendukung dan memperlihatkan kepada top manajemen bahwa unit ini bisa memberikan hasil yang maksimal perlu dilakukan, dalam penelitian ini mencari apakah ada pengaruh dari latar belakang yang telah disampaikan mengenai permasalahan yang ada pada budaya kerja dengan kinerja kerja.

\section{METODE PENELITIAN}

Metode Penelitian dalam penelitian ini menggunakan survei dimana populasinya adalah warga masyarakat dan sampel yang digunakan dalam penelitian ini adalah total sampling, dengan total sampling, diambil sampel sebanyak 47 karyawan pada Unit Cargo PT. Garuda Indonesia (Distrik Jakarta Raya). Data yang digunakan adalah data primer yaitu data yang didapat dari jawaban responden dari serangkaian pertanyaan/pernyataan yang diajukan oleh peneliti dalam kuesioner sebanyak duabelas pertanyaan untuk masing-masing variabel. Kuesioner digunakan untuk dapat mengetahui tanggapan para responden terhadap pertanyaan/pernyataan yang diberikan. Dengan begitu responden dapat dengan mudah memberikan jawaban alternatif yang sudah disediakan dan juga tidak memakan waktu lama. Data yang digunakan adalah data primer yaitu data yang didapat dari jawaban responden dari serangkaian pertanyaan yang diajukan oleh peneliti dalam kuesioner.

Data yang digunakan adalah data primer yaitu data yang didapat dari jawaban responden dari serangkaian pertanyaan/pernyataan yang diajukan oleh peneliti dalam kuisioner. Kuesioner digunakan untuk dapat mengetahui tanggapan para responden terhadap pertanyaan/pernyataan yang diberikan. Dengan begitu responden dapat dengan mudah memberikan jawaban alternatif yang sudah disediakan dan juga tidak memakan waktu lama.

Pengukuran indikator variabel penelitian ini menggunakan Skala Likert, yaitu dengan menyusun pertanyaan atau pernyataan yang masing-masing item diberi range skor dalam Skala Likert. Skala Likert menggunakan lima tingkatan jawaban sebagai berikut :

\section{Tabel 1 Instrumen Skala Livert}

\begin{tabular}{|c|l|c|}
\hline No & \multicolumn{1}{|c|}{ Skala } & Skor \\
\hline 1 & Sangat Setuju (SS) & 5 \\
\hline 2 & Setuju (S) & 4 \\
\hline 3 & Netral (N) & 3 \\
\hline 4 & Tidak Setuju (TS) & 2 \\
\hline 5 & $\begin{array}{l}\text { Sangat Tidak } \\
\text { Setuju (STS) }\end{array}$ & 1 \\
\hline
\end{tabular}


Sumber: Sugiyono $(2007: 105)$

Metode Analisis data yang digunakan dalam penelitian ini adalah uji masing-masing variabel (menguji variabel $\mathrm{X}$ dan $\mathrm{Y}$ masingmasing sehingga dinyatakan valid dari suatu kuesioner yang dibagikan kepada responden), Uji Reabilitas masing-masing variabel (suatu kuesioner dinyatakan reliabel apabila nilai $r_{\text {hitung }}>$ nilai $r_{\text {tabel }}$ dengan taraf signifikan 5\%). Analisis Regresi Linier Sederhana merupakan analisis yang ingin mengetahui sampai berapa jauh perubahan satu variabel terhadap variabel lainnya, dengan rumus sebagai berikut ;

$$
\hat{\mathbf{Y}}=\mathbf{a}+\mathbf{b} \mathbf{X}
$$

Uji parsial ( $t$ test) untuk mengetahui pengaruh masing-masing variabel independen terhadap variabel dependen. Dengan menggunakan rumus sebagai berikut:

$$
t=\frac{r \sqrt{n-2}}{\sqrt{1-r^{2}}}
$$

Uji pengaruh stimultan ( $F$ test) untuk mengetahui apakah variabel independen secara bersama-sama atau stimultan mempengaruhi variabel dependen.

Maka dapat dianalisis dengan menggunakan rumus sebagai berikut:

$$
F=\frac{\mathrm{R}^{2} /(\mathrm{k}-1)}{\left(1-\mathrm{R}^{2}\right)(n-k-1)}
$$

Koefisien determinasi untuk mengukur seberapa jauh kemampuan model dalam menerangkan variasi variabel independen. dengan rumusan mencari pengaruh antar variabel $\mathrm{x}$ dan $\mathrm{y}$, dengan rumus:

$$
\mathrm{KD}=\mathrm{r}^{2} \times 100 \%
$$

\section{PEMBAHASAN DAN HASIL}

Hasil Uji Validitas Variabel Budaya Kerja (X)

Tabel Hasil Uji Validitas Variabel Budaya

Kerja

Tabel 1 
Sumber: Hasil Olahan Data (SPSS 21), 2019

Dari hasil tabel di atas maka di dapatkan hasil, df $=\mathrm{N}-1$ atau df $10-1=9$ dan tingkat signifikan 5\% maka diperoleh nilai $\mathbf{r}_{\text {tabel }} 0.666$. Sehingga untuk melihat $\mathbf{r}_{\text {hasil }}$ dapat dilihat pada tabel uji validitas variabel Budaya Kerja (X), dimana didapatkan nilai $\mathbf{r}_{\text {hasil }}$ positif dan lebih besar dari $\mathbf{r}_{\text {tabel }}(0.666)$ maka variabel Budaya Kerja (X) dapat dinyatakan valid yakni pertanyaan pertama sebesar 0.745 , pertanyaan kedua sebesar 0.686 , pertanyaan ketiga sebesar 0.914, pertanyaan keempat sebesar 0.782, pertanyaan kelima sebesar 0.769 , pertanyaan keenam sebesar 0.667, pertanyaan ketujuh sebesar 0.825, pertanyaan kedelapan sebesar 0.844, pertanyaan kesembilan sebesar 0.718 , serta pertanyaan kesepuluh sebesar 0.920 . Sehingga ditinjau dari keseluruhan yang dinyatakan valid $100 \%$.

Hasil Uji Validitas Variabel Kinerja Kerja (Y)

\section{Hasil Uji Validitas Kinerja Kerja (Y) Tabel 2}

\begin{tabular}{c|c|c|c} 
Perta & \multicolumn{3}{|c}{ Kinerja Kerja (Y) } \\
\cline { 2 - 4 } $\begin{array}{c}\text { nyaa } \\
\text { n }\end{array}$ & $\mathbf{r}_{\text {hitung }}$ & $\mathbf{r}_{\text {tabel }}$ & $\begin{array}{c}\text { Keteran } \\
\text { gan }\end{array}$ \\
\hline 1 & 0.78 & 0.66 & Valid \\
2 & 4 & 6 & Valid \\
3 & 0.78 & 0.66 & Valid \\
4 & 4 & 6 & Valid \\
5 & 0.79 & 0.66 & Valid \\
6 & 8 & 6 & Valid \\
7 & 0.93 & 0.66 & Valid \\
8 & 8 & 6 & Valid \\
9 & 0.72 & 0.66 & Valid \\
10 & 4 & 6 & Valid
\end{tabular}

\begin{tabular}{c|c|c|c}
\multirow{2}{*}{ Pertanyaan } & \multicolumn{3}{|c}{ Budaya Kerja (X) } \\
\cline { 2 - 4 } & $\mathbf{r}_{\text {hitung }}$ & $\mathbf{r}_{\text {tabel }}$ & Keterangan \\
\hline \hline 1 & 0.745 & 0.666 & Valid \\
2 & 0.686 & 0.666 & Valid \\
3 & 0.914 & 0.666 & Valid \\
4 & 0.782 & 0.666 & Valid \\
5 & 0.769 & 0.666 & Valid \\
6 & 0.667 & 0.666 & Valid \\
7 & 0.825 & 0.666 & Valid \\
8 & 0.844 & 0.666 & Valid \\
9 & 0.718 & 0.666 & Valid \\
10 & 0.920 & 0.666 & Valid \\
\hline & 1 & 6 & \\
& 0.75 & 0.66 & \\
& 8 & 6 & \\
& 0.68 & 0.66 & \\
& 0 & 6 & \\
& 0.74 & 0.66 & \\
& 5 & 6 & \\
& 0.73 & 0.66 & \\
Sumber: Hasil Olahan Data (SPSS 21$), 2019$ & 6 & \\
\hline
\end{tabular}

Dari hasil tabel di atas maka di dapatkan hasil, $\mathrm{df}=\mathrm{N}-1$ atau $\mathrm{df}=10-1=9$ dan tingkat signifikan 5\% maka peroleh nilai $\mathbf{r}_{\text {tabel }} 0.666$. Sehingga untuk melihat $\mathbf{r}_{\text {hasil }}$ dapat dilihat pada tabel uji validitas Kinerja Kerja (Y), oleh karena hasilnya positif dan lebih besar dari $\mathbf{r}_{\text {tabel }}$ 0.666, maka variabel Kinerja Kerja (Y) yakni pertanyaan pertama sebesar 0.784 , pertanyaan kedua sebesar 0.784 , pertanyaan ketiga sebesar 0.798, pertanyaan keempat sebesar 0.938, pertanyaan kelima sebesar 0.724 , pertanyaan keenam sebesar 0.741, pertanyaan ketujuh sebesar 0.758, pertanyaan kedelapan sebesar 0.680, pertanyaan kesembilan sebesar 0.745, pertanyaan kesepuluh sebesar 0.732. Dimana secara keseluruhan dapat dinyatakan valid sebesar $100 \%$. 
Hasil Uji Reabilitas Variabel Budaya Kerja

Hasil Uji Reliabilitas Variabel Budaya Kerja

(X)

\section{Tabel 3}

\section{Reliability statistic}

\begin{tabular}{|c|c|}
\hline Cronbach's Alpha & N of items \\
\hline $\mathbf{. 9 3 6}$ & $\mathbf{1 0}$ \\
\hline
\end{tabular}

Berdasarkan hasil tabel di atas, maka Uji Reliabilitas variabel Budaya Kerja (X) di dapatkan hasil dengan nilai $\mathbf{r}_{\text {tabel }}$ 0.666, sedangkan nilai Alpha sebesar 0.936 sehingga dapat disimpulkan bahwa $\mathbf{r}_{\text {Alpha }}$ positif dan lebih besar atau $0.936>0.666$ maka dengan demikian instrumen penelitian variabel Budaya Kerja (X) adalah Reliabel.

Hasil Uji Reabilitas Variabel Kinerja Kerja (Y)

\section{Hasil Uji Relliabilitas Variabel Kinerja Kerja (Y) \\ Tabel 4}

\section{Reliability statistic}

\begin{tabular}{|c|c|}
\hline Cronbach's Alpha & N of items \\
\hline .858 & 10 \\
\hline
\end{tabular}

Berdasarkan hasil tabel di atas maka didapatkan hasil Uji Reliabilitas variabel Kinerja Kerja (Y) dengan Nilai $\mathbf{r}_{\text {tabel }}$ 0.666, sedangkan nilai Alpha 0.858 sehingga dapat disimpulkan bahwa Alpha positif dan lebih besar atau $0.858>0.666$ maka instrumen variabel Kinerja Kerja (Y) adalah Reliabel.

\begin{tabular}{l|c|c|c|c}
\hline \hline Variabel & Nilai & $\begin{array}{c}\text { Standard } \\
\text { Error }\end{array}$ & $\mathbf{t}_{\text {hitung }}$ & $\mathbf{t}_{\text {tabel }}$ \\
\hline \hline $\begin{array}{l}\text { Budaya } \\
\text { Kerja (X) }\end{array}$ & 0,621 & 0,086 & 7.260 & 1,680 \\
\hline \multicolumn{4}{l|}{ Hasil Uji Koefisien Determinasi }
\end{tabular}

Karena nilai tersebut belum menunjukkan besaran pengaruh, maka besar pengaruh tersebut dihitung secara manual dengan menggunakan rumus koefisien determinasi sebagai berikut : $\mathrm{KD}=\mathrm{r}^{2} \times 100 \%$. Dimana $r$ adalah nilai hasil analisis koefisien korelasi sebesar 0,734. Hasil perhitungan selanjutnya sebagai berikut :

$$
\begin{aligned}
\text { KD } & =\mathbf{R}^{2} \times 100 \% & & =\mathbf{0 , 7 3 4} \times 100 \% \\
& =0,539 \times 100 \% & & =53,9 \%
\end{aligned}
$$

Dengan hasil tersebut diatas dapat dikatakan bahwa variabel Budaya Kerja (X) terhadap variabel Kinerja Kerja (Y) ada pengaruh sebesar $53,9 \%$ dan sisanya $46,1 \%$ disebabkan oleh faktor-faktor yang lainnya. Hasil Uji t

\section{Hasil Uji t}

Berdasarkan hasil uji t tersebut di atas, bahwa secara nyata variabel Budaya Kerja (X) mempunyai pengaruh yang kuat terhadap variabel Kinerja Kerja (Y) dimana nilai $t_{\text {hitung }}>$ 


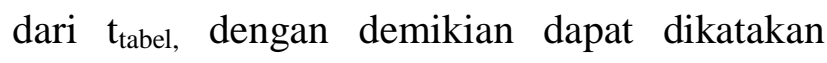
bahwa $\mathrm{H}_{0}$ ditolak $\mathrm{H}_{1}$ diterima.

Hasil Penelitian di atas dibuktikan dari beberapa pengujian dan mendapatkan hasil yang sedang dengan tingkat keterkaitan satu variabel dengan variabel lain (X-Y) yaitu 53,9\%.

\section{KESIMPULAN}

Setelah dilakukan analisa bahwa ternyata variabel Budaya Kerja dapat meningkatkan Kinerja Kerja diperoleh nilai sangat baik ada pengaruh positif terhadap Kinerja Kerja sesuai harapan pimpinan. Hasil analisa dan uji hipotesisnya dinyatakan bahwa terdapat pengaruh positif antara variabel Budaya Kerja (X) terhadap variabel Kinerja Kerja (Y) diperoleh nilai $\mathrm{R}$ sebesar 0,734 dan sedangkan nilai $\mathrm{R}$ Square sebesar 0,539 atau $53,9 \%$ sehingga dapat disimpulkan bahwa pengaruhnya sedang, maka peru dilakukan uji hipotesis variabel Budaya Kerja (X) yang diperoleh nilai $\mathrm{t}_{\text {hitung }}=7,260>\mathrm{t}_{0,05(45)}=1,680$ maka $\mathrm{H}_{\mathrm{o}}$ ditolak dan $\mathrm{H}_{\mathrm{a}}$ diterima yang berarti mempunyai bukti, bahwa antara variabel Budaya Kerja (X) terhadap variabel Kinerja Kerja (Y) terdapat pengaruh signifikan.

\section{DAFTAR PUSTAKA}

Abraham Maslow dalam Anwar Prabu Mangkunegara, 2005. Teori Motivasi, Bandung. Penerbit PT. Remaja Rosdakarya.
Abraham Maslow dalam Sondang P. Siagian, 2005. Manajemen Sumber Daya Manusia, Bandung. Penerbit ALFABETA.

Anwar Prabu Mangkunegara, 2005. Manajemen Sumber Daya Manusia Perusahaan, Penerbit, PT. Remaja Rosdakarya, Bandung.

Arikunto, Suharsimi, 2005. "Prosedur Penelitian Suatu Pendekatan Praktek", Cetakan Kedua, Penerbit CV. Alfabeta, Bandung.

Bastian, 2001, Manajemen Personalia, Badan Penerbit Rajawali Pers. Jakarta.

Bedjo Siswanto Sastrohadiwiryo, 2002, Manajemen Sumber Daya Manusia, Badan Penerbit Grasindo Gramedia Jakarta.

Gibson, Ivancevich, Donnelly. 2004. Organisasi. Jakarta: Alih bahasa Nunuk Adiarni, edisi kedelapan, Binarupa Aksara.

Hadari Nawawi, 2005. Metode Penelitian Bidang Sosial, Penerbit Gajah Mada Universitas Press, Yogyakarta.

Halim, 2002, Manajemen Sumber Daya Manusia, Edisi ke-9, PT. Gunung Agung, Jakarta.

Hasibuan, Malayu SP, 2005. Manajemen Sumber Daya Manusia, Edisi ke-9, PT. Gunung Agung, Jakarta.

Husein Umar, 2005. Riset Sumber Daya Manusia Dalam Organisasi, Penerbit Rajawali Pers. Jakarta.

J. Supranto. 2011, Analisis Multi Variat Arti Dan Prestasi. Rineka Cipta. Jakarta. 
Mc. Gregor dalam Malayu SP. Hasibuan, 2007, Manajemen Sumber Daya manusia, Penerbit PT. Bumi Aksara, Jakarta.

Nana Sudjana, 2004, Teknologi Pengajaran, Badan Penerbit Sinar Baru Algesindo. Bandung.

Riduwan, 2007, Skala Pengukuran Variabel-variabel Penelitian, Badan Penerbit, ALFABETA, Bandung.

Santoso, Singih,. 2002. SPSS Versi 12 Mengolah Data Statistik Secara Profesional, PT. Elex Media Komputindo, Jakarta.

Sondang P. Siagian, 2007, Manajemen Sumber Daya Manusia, Badan Penerbit Bumi Aksara, Jakarta

Sonny Harsono, 2004, Skala Pengukuran Variabel-variabel Penelitian, Badan Penerbit, ALFABETA, Bandung.

Sugiyono, 2008. Metode Penelitian Administrasi, Badan Penerbit, CV. Alfabeta, Bandung.

Suliyanto, 2006, Metode Riset Bisnis, Badan Penerbit, ANDI, Yogyakarta.

Surahkmad, 2005, Ciri-Ciri Asosiatif,

Badan Penerbit, ALFABETA, Bandung.

Susilo Martoyo, 2005, Manajemen Sumber Daya Manusia Perusahaan, Penerbit, PT. Remaja Rosdakarya, Bandung. 